\title{
Convergence of relative pollution levels among the countries of the Baltic Sea region
}

\author{
Jacek Batóg*, Barbara Batóg \\ Department of Econometrics and Statistics, Faculty of Economics and Management, University of Szczecin, Szczecin, Poland
}

\begin{abstract}
In the present study, the concept of absolute and marginal convergence was applied to evaluate relative emissions trends for basic types of pollution within the countries of the Baltic Sea region. The proposed measure of relative pollution is an indicator for the ecological effectiveness of the analyzed economies. We tested the following hypotheses: (1) the relative levels of pollution among the countries of the Baltic Sea region are characterized by the same long-term equilibrium; (2) the dispersion of pollution diminishes over time. Convergence applies for the relative emissions of acidifying substances, greenhouse gases, and particulate matter. The contributions of the countries' relative levels of pollution to the process of overall convergence were also estimated by means of a new concept of marginal vertical convergence. The results indicate that the estimated contributions vary from country to country.
\end{abstract}

KEY WORDS: Pollution · Convergence

Resale or republication not permitted without written consent of the publisher

\section{INTRODUCTION}

The effects of pollution and climate change are frequently discussed in terms of contemporary social and economic processes (e.g. Nishioka et al. 2006, Ebi \& McGregor 2008, Harris 2008). The effects of environmental factors on the dynamics of economic growth is so large that there is a need to revise the basic measures of growth that have been utilized thus far. According to the most recent proposals by the European Commission, the new 'green' sustainable development indicator formula will incorporate climate change, energy consumption, level of biodiversity, pollution of air and water and its effects on human health, water management, the use of natural resources, and certain social factors (see e.g. Goossens et al. 2007, Stiglitz et al. 2009, European Commission 2010).

Research studies into the level of pollution and other forms of degradation of the natural environment have, until recently, mostly been based on absolute values of the analyzed variables (e.g. Alvarez et al. 2004, EEA 2004, Kerr 2007). In these analyses, which attempt to define whether there is a long-term balance point (i.e. a shared steady-state level) describing all countries in question in terms of a particular type of pollution, relative measures of pollution per capita have been used
(Heil \& Wodon 1999, Strazicich \& List 2003, Stegman 2005).

The approach recommended in the present study uses relative measures of pollution in which the denominator describes the size of the economy expressed as its gross domestic product (GDP). We obtain a measure defined as the amount of pollution per GDP unit, which allows assessment of the ecological effectiveness of the analyzed economy. Low values of this measure indicate a high potential for reduction of the amount of pollution. This relative pollution approach takes into account both the size and the ecological effectiveness of economies when analysing the effect of an economic process on the degradation of the natural environment.

The main goal of the present study was to evaluate and compare the processes leading to a reduction in relative pollution in the developed and developing countries within the Baltic Sea region (BSR). The relative approach is based on the assumption that lessdeveloped countries are characteristically quicker at environmental improvement. If such an assumption is not true, then we would observe a weak or even lack of income convergence among the examined countries in cases where the environmental factor is incorporated into the green accounting of GDP (a recent study of 
income convergence among European Union countries was presented in Batóg \& Batóg 2006).

Previous analyses of pollution-level convergence were based on the distributional approach (inter alia) in the sense of stochastic kernel estimation, which suggests that the cross-country distribution of emissions per capita is characterized by persistence. Since there is a lack of convergence, in an absolute sense, in emissions per capita across countries, projection models that generate convergence in emissions per capita are inconsistent with their observed behavior (Stegman 2005) $)^{1}$.

Some authors also used the stochastic approach (see e.g. Bernard \& Durlauf 1995) to examine convergence in emissions per capita by applying panel unit root tests (Strazicich \& List 2003) and the decompositions of the Gini index (Heil \& Wodon 1999) to analyze convergence in projected emissions per capita.

In order to verify the main hypotheses, we assessed whether relative levels of pollution are characterized by the same long-term equilibrium and whether their dispersion diminishes over time. Using a new conceptual model of marginal vertical convergence, we identified the contribution of individual countries to the process of total convergence.

\section{METHODOLOGY AND SAMPLE}

In the present study, 3 kinds of convergence analysis were applied: $\sigma$-convergence, absolute $\beta$-convergence, and marginal vertical $\beta$-convergence.

$\sigma$-convergence is an alternative to the Gini index and applies if the dispersion of pollution levels for economies tends to decrease over time. In the present paper, the examination of $\sigma$-convergence was based on the estimation of a linear trend of standard deviations of relative pollution:

$$
\sigma=\delta_{0}+\delta_{1} t+\varepsilon_{t}
$$

where $\sigma$ is the standard deviation of logarithms of relative pollution, $t$ is a time variable, $\delta_{0}$ and $\delta_{1}$ are parameters of linear trends, and $\varepsilon_{t}$ is random error.

Absolute $\beta$-convergence is an alternative to the distributional and stochastic approaches and applies if countries with low and high levels of pollution tend to reach the same long-run equilibrium (see e.g. Aghion \& Howitt 1999, Barro \& Sala-i-Martin 2004). This kind of

\footnotetext{
15ome researchers came to quite different conclusions. For instance, Criado et al. (2009) analyzed the spatial distributions of per capita emissions and showed that cross-country pollution gaps have decreased over the period for nitrogen oxides $\left(\mathrm{NO}_{\mathrm{x}}\right)$ and sulfur oxides $\left(\mathrm{SO}_{\mathrm{x}}\right)$ within Eastern as well as Western European areas
}

convergence is described by the equation of absolute $\beta$-convergence for discrete periods of unit length:

$$
\frac{1}{T} \ln \left(\frac{y_{i, T}}{y_{i, 0}}\right)=a-\left[\frac{\left(1-e^{-\beta T}\right)}{T}\right] \ln \left(y_{i, 0}\right)+u_{i T}
$$

where the expression on the left-hand side of Eq. (2) represents the average annual growth rate of relative pollution in country $i$ at time $T, y_{i, T}$ is the level of relative pollution in country $i$ at time $T$, $a$ is an intercept, $u$ is random error, $\beta$ is the convergence rate and $y_{i, 0}$ is the initial level of relative pollution in country $i$.

The rate of $\beta$-convergence can be calculated using the formula:

$$
\beta=-\frac{1}{T} \cdot \ln \left(1+\alpha_{1} \cdot T\right)
$$

The term $\alpha_{1}$, the slope in Eq. (2), can be obtained by rearranging Eq. (3a) in the following manner:

$$
\alpha_{1}=-\left(\frac{1-e^{-\beta T}}{T}\right)
$$

Therefore the value of $\alpha_{1}$ is obtained by the estimation of Eq. (2).

The half-life of convergence $\left(T_{1 / 2}\right)$ is the time at which the convergence process is halfway between the initial and the steady-state level and is given using the formula:

$$
T_{1 / 2}=\frac{\ln 2}{\beta}
$$

It should be pointed out that the absolute $\beta$-convergence analysis is not robust with regard to the choice of the examined period (1990 to 2006), especially its initial year.

The classical convergence approaches ( $\beta$ and $\sigma$ ) do not differentiate between the speeds of convergence for individual countries. As a solution to this problem, the marginal vertical $\beta$-convergence could be applied. The idea of this kind of convergence is described by the formula:

$$
\beta_{i}=\beta-\beta_{i}^{N-1}
$$

where $\beta_{i}$ is the value of marginal vertical convergence for country $i, \beta$ is the rate of convergence calculated for $N$ countries, and $\beta_{i}^{N-1}$ is the rate of convergence calculated for $N-1$ countries (excluding country $i$ ).

The marginal vertical $\beta$-convergence allows us to assess the contribution of a given country to the process of total convergence for the whole set of examined objects.

The present research concerned 4 kinds of relative pollution: A: emissions of acidifying substances (tonnes of acid equivalent per 1000 units of $\mathrm{GDP}^{2}$ ), B: emissions

\footnotetext{
${ }^{2} \mathrm{GDP}$ is expressed in 2007 US dollars (converted to 2007 price levels with updated 2005 Elteto-Koves-Szulc [EKS] purchasing power parities [PPPs])
} 
of greenhouse gases (tonnes of $\mathrm{CO}_{2}$ equivalent per unit of GDP), C: emissions of ozone precursors (tonnes of ozone-forming potential per 1000 units of GDP), and D: emissions of particulate matter (tonnes of particulateforming potential per 1000 units of GDP). The emissions of acidifying pollutants, greenhouse gases, and ozone precursors are defined according to the Convention on Long-range Transboundary Air Pollution (LRTAP Convention, www.unece.org/env/lrtap/), the United Nations Framework Convention on Climate Change (UNFCCC, http://unfccc.int/essential_background/items/2877. php), and the European Union (EU, http://rod.eionet. europa.eu/instruments/592) Greenhouse Gas Monitoring Mechanism. The emissions of acidifying pollutants include nitrogen oxides $\left(\mathrm{NO}_{\mathrm{x}}\right)$, sulfur dioxide $\left(\mathrm{SO}_{2}\right)$, and ammonia $\left(\mathrm{NH}_{3}\right)$. The greenhouse emission gases include all of the greenhouse gases covered by the Kyoto Protocol, (http://unfccc.int/kyoto_protocol/items/2830.php) $\left(\mathrm{CO}_{2}, \mathrm{CH}_{4}, \mathrm{~N}_{2} \mathrm{O}, \mathrm{SF}_{6}\right.$, hydrofluorocarbons [HFCs], and perfluorocarbons [PFCs]). They do not include the greenhouse gases that are also ozone-depleting substances and which are regulated by the Montreal Protocol (http://ozone.unep.org/). The emissions of ozone precursors include ground-level ozone precursors $\left(\mathrm{NO}_{\mathrm{x}}\right.$ non-methane volatile organic compounds [NMVOCs], $\mathrm{CO}$, and $\mathrm{CH}_{4}$ ). Emissions of primary particulate matter and secondary particulate precursors $\left(\mathrm{NO}_{\mathrm{x}}, \mathrm{SO}_{2}\right.$, and $\mathrm{NH}_{3}$ ), called PM10 and PM2.5 respectively, are defined by the European Environment Agency (EEA, www.eea. europa.eu) as fine solid or liquid particles added to the atmosphere by processes originating from the Earth's surface. Particulate matter includes dust, smoke, soot, pollen, and soil particles.

The primary annual data of absolute levels of emissions for the 8 countries in the BSR (Denmark, Estonia, Finland, Germany, Latvia, Lithuania, Poland, and Sweden) for the period 1990 to 2006 were collected from the Eurostat Database (http://epp.eurostat.ec.europa.eu). GDP data comes from The Conference Board and Groningen Growth and Development Centre, Total Economy Database, January 2008 (data - now updated available at www.conference-board.org/data/economydatabase/) The spatial range of data was constrained to BSR countries to assure the homogeneity of the examined countries according to their anthroposphere characteristics. The analyzed period was limited by the availability of the latest data on pollutions.

\section{RESULTS}

The time series of the examined relative pollutions are presented in Fig. 1. The data show that all considered relative emissions of pollutions were characterized by diminishing trends. In the early 1990s, Estonia and Poland reported the highest levels of all the examined relative pollution types. The levels of relative pollution in Lithuania and Latvia were lower than in Estonia and Poland but higher than in the remaining analyzed countries (the 4 'older' EU members). The lowest levels of relative pollution were reported in Sweden and Germany. At the beginning of the examined period, the dispersions of values of all types of pollution were much greater than in 2006 .

Meaningful correlations can be drawn based on the observation of changes in the components of relative pollution, i.e. absolute levels of pollution and levels of GDP. The highest absolute levels of all 4 types of pollution were registered for Germany and Poland.

In the case of absolute levels of Pollution A (data not shown), a significant decrease was observed in Germany and Poland, whereas the reduction was much slower in Estonia, Lithuania, and Latvia. In the period 2001 to 2006, the decrease in absolute levels of Pollution $\mathrm{A}$ in these latter 3 countries was almost unnoticeable. In the case of Pollution $B$, its absolute level in the examined years was similar in all the countries apart from Germany. Therefore, one can deduce that the decrease in the relative levels of Pollution B was caused by growth in GDP. The absolute level of Pollution $\mathrm{C}$ hardly changed in Estonia, Latvia, Lithuania, and Poland, in contrast to the rest of the examined countries, in which a decrease in Pollution $\mathrm{C}$ was evident. As for Pollution D, its absolute level did not decrease in Latvia, Lithuania, and Poland.

Even in the cases where a reduction in absolute emissions of pollutions was not observed, we can draw the conclusion that the phenomenon of GDP growth in BSR countries makes those countries more environmentally friendly (see Fig. 1).

Eqs. (6) to (9) present the estimated models of absolute $\beta$-convergence of the relative emissions of Pollutions A, $B, C$, and D, respectively ( $t$-statistics are in parentheses).

$$
\begin{aligned}
& \frac{1}{T} \cdot \ln \left(\frac{A_{T}}{A_{0}}\right)=\underset{(-4.91)}{-0.230}-\underset{(-3.23)}{0.018} \cdot \ln A_{0} \text {, } \\
& \mathrm{R}^{2}=0.635 \quad \beta=2.09 \% \quad T_{\frac{1}{2}}=33.17 \mathrm{yr} \\
& \frac{1}{T} \cdot \ln \left(\frac{B_{T}}{B_{0}}\right)=\underset{(-4.64)}{-0.247}-\underset{(-3.87)}{0.029} \cdot \ln B_{0} \\
& \mathrm{R}^{2}=0.714 \quad \beta=3.86 \% \quad T_{1 / 2}=17.94 \mathrm{yr}
\end{aligned}
$$

$$
\begin{aligned}
& \frac{1}{T} \cdot \ln \left(\frac{C_{T}}{C_{0}}\right)=\underset{(-1.20)}{-0.087}-\underset{(-0.43)}{0.006} \cdot \ln C_{0} \\
& \mathrm{R}^{2}=0.030 \quad \beta=0.65 \% \quad T_{1 / 2}=106.36 \mathrm{yr}
\end{aligned}
$$

$$
\begin{aligned}
& \frac{1}{T} \cdot \ln \left(\frac{D_{T}}{D_{0}}\right)=\underset{(-4.61)}{0.152}-\underset{(-2.54)}{0.016} \cdot \ln D_{0} \\
& \mathrm{R}^{2}=0.519 \quad \beta=1.81 \% \quad T_{1 / 2}=38.33 \mathrm{yr}
\end{aligned}
$$



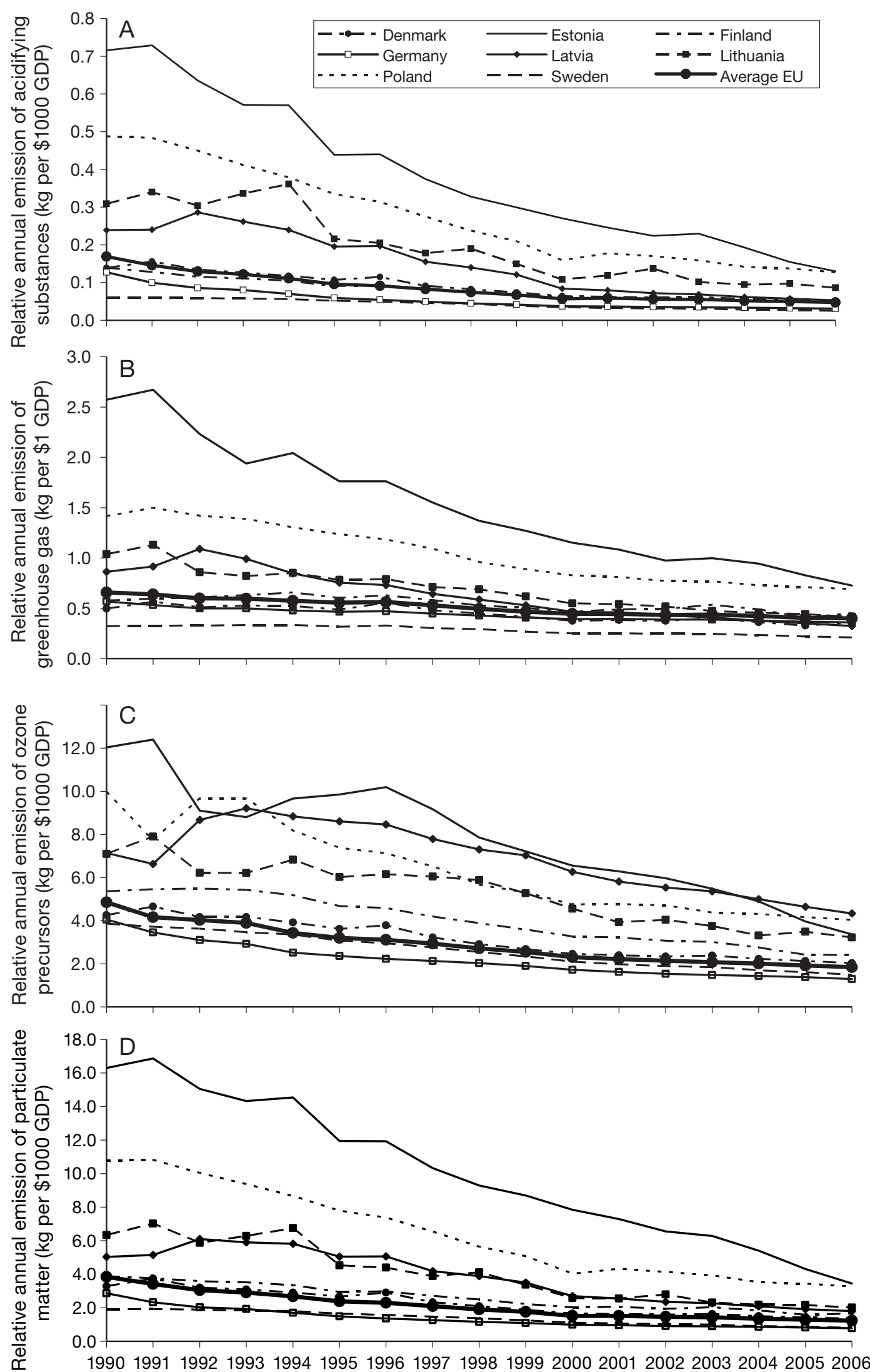

Fig. 1. Relative annual emissions. (A-D) Pollution categories A to D. (A) Acidifying substances, (B) greenhouse gases, (C) ozone precursors, (D) particulate matter. Calculations based on Eurostat and The Conference Board and Groningen Growth and Development Centre, Total Economy Database data. EU average was calculated for 27 countries. Note the different $y$-axis unit for (B) 
It can be observed that in the case of emissions of Pollution $\mathrm{A}, \mathrm{B}$, and $\mathrm{D}$, convergence applies. For these 3 kinds of pollution, all the parameters are statistically significant. The speed of convergence varies from $1.81 \%$ for the relative emission of particulate matter to $3.86 \%$ for the relative emission of greenhouse gases. This means that in 20 to $40 \mathrm{yr}$, the relative levels of Pollutions $\mathrm{A}, \mathrm{B}$, and D will reach the half-way point of their steady states (long-term equilibriums). The resulting estimates of $\beta$ for the relative emission of Pollution $C$, however, does not confirm the convergence hypothesis.

All the above conclusions (previous paragraph) are confirmed by the results of the $\sigma$-convergence analysis. Fig. 2 shows the behavior of standard deviations of the examined relative pollutions (in logarithms) during the examined 1990-2006 period. Negative tendencies are evident for Pollution A, B, and D over the analyzed period, while in the case of Pollution $C_{\text {, dispersion }}$ started decreasing in 1997.

The estimated linear trends of the $\sigma$-convergence results are shown in Eqs. (10) to (13), for Pollution A to $D$, respectively. For the relative levels of Pollutions $A$, $\mathrm{B}$, and $\mathrm{D}$, the occurrence of diminishing dispersion can be seen in Eqs. (10), (11), \& (13) respectively ( $t$-statistics are in parentheses). These 3 estimated models of linear trends are characterized by very high values of the coefficient of determination and by statistically significant slopes. Only in the case of emissions of ozone precursors (Pollution C; Eq. 12) is convergence not visible.

$$
\begin{aligned}
& \sigma_{A}=\underset{(69.32)}{0.82228}-\underset{(-11.49)}{0.013304} \cdot t, \quad \mathrm{R}^{2}=0.898 \\
& \sigma_{B}=\underset{(63.73)}{0.618586}-\underset{(-16.16)}{0.015308} \cdot t, \quad \mathrm{R}^{2}=0.946 \\
& \sigma_{C}=\underset{(27.56)}{0.438183}+\underset{(1.09)}{0.001685} \cdot t, \quad \mathrm{R}^{2}=0.073 \\
& \sigma_{D}=\underset{(53.91)}{0.728535-\underset{(-6.98)}{0.009201} \cdot t,} \quad \mathrm{R}^{2}=0.764
\end{aligned}
$$

The resulting calculations for the marginal vertical convergence for the relative levels of the 2 selected Pollutants A and B are presented in Table 1 and Fig. 3.
Table 1. Marginal vertical convergence for relative emission of acidifying substances and greenhouse gases (Pollution A and $B$, respectively). $\left(\alpha_{1 \mathrm{i}}\right)$ : slope of linear model (Eq. 2) estimated for $N-1$ countries (excluding country $i) ;\left(\beta_{i}^{N-1}\right)$ rate of convergence calculated for $N-1$ countries (excluding country $i)_{i}\left(T_{1 / 2}^{i}\right)$ half-life of convergence calculated for $N-1$ countries (excluding country $i) ;\left(\beta_{i}\right)$ value of marginal vertical convergence for country $i$ (Eq. 5); $\left(\Delta T_{1 / 2}^{i}\right)$ difference between the half-life of convergence calculated for $N$ countries and for $N-1$ countries (excluding country $i$ ). Countries are ordered according to increasing values of parameter $\alpha_{1 \mathrm{i}}$

\begin{tabular}{|lrrrrr|}
\hline \multicolumn{7}{|c}{$\alpha_{1 i}$} & $\beta_{i}^{N-1}$ & $T_{1 / 2}^{i}(\mathrm{yr})$ & $\beta_{i}$ & $\Delta T_{1 / 2}^{i}(\mathrm{yr})$ \\
\hline Pollution A & & & & & \\
Poland & -0.0203 & 0.0246 & 28.19 & 0.0037 & -4.98 \\
Germany & -0.0202 & 0.0244 & 28.37 & 0.0035 & -4.80 \\
Lithuania & -0.0184 & 0.0218 & 31.83 & 0.0009 & -1.34 \\
Latvia & -0.0174 & 0.0203 & 34.10 & -0.0006 & 0.93 \\
Denmark & -0.0168 & 0.0196 & 35.33 & -0.0013 & 2.16 \\
Finland & -0.0168 & 0.0196 & 35.34 & -0.0013 & 2.17 \\
Sweden & -0.0160 & 0.0185 & 37.57 & -0.0024 & 4.40 \\
Estonia & -0.0149 & 0.0171 & 40.63 & -0.0038 & 7.46 \\
& & & & & \\
Pollution B & & & & & \\
Sweden & -0.034 & 0.0500 & 13.88 & 0.0113 & -4.06 \\
Poland & -0.032 & 0.0448 & 15.46 & 0.0062 & -2.48 \\
Germany & -0.028 & 0.0379 & 18.30 & -0.0008 & 0.36 \\
Latvia & -0.028 & 0.0377 & 18.36 & -0.0009 & 0.42 \\
Lithuania & -0.028 & 0.0372 & 18.63 & -0.0014 & 0.69 \\
Denmark & -0.027 & 0.0361 & 19.22 & -0.0026 & 1.28 \\
Finland & -0.027 & 0.0348 & 19.92 & -0.0038 & 1.98 \\
Estonia & -0.026 & 0.0328 & 21.15 & -0.0059 & 3.21 \\
\hline
\end{tabular}

These results indicate that some countries make a greater contribution to the process of convergence of relative pollution. For the relative emission of acidifying substances, Poland and Germany have tended toward a lower speed of absolute convergence, while Estonia and Sweden are inversely affected. For the relative emission of greenhouse gases, a diminishing rate of convergence can be observed for Sweden and Poland, while an increasing rate is observed for Estonia and Finland.

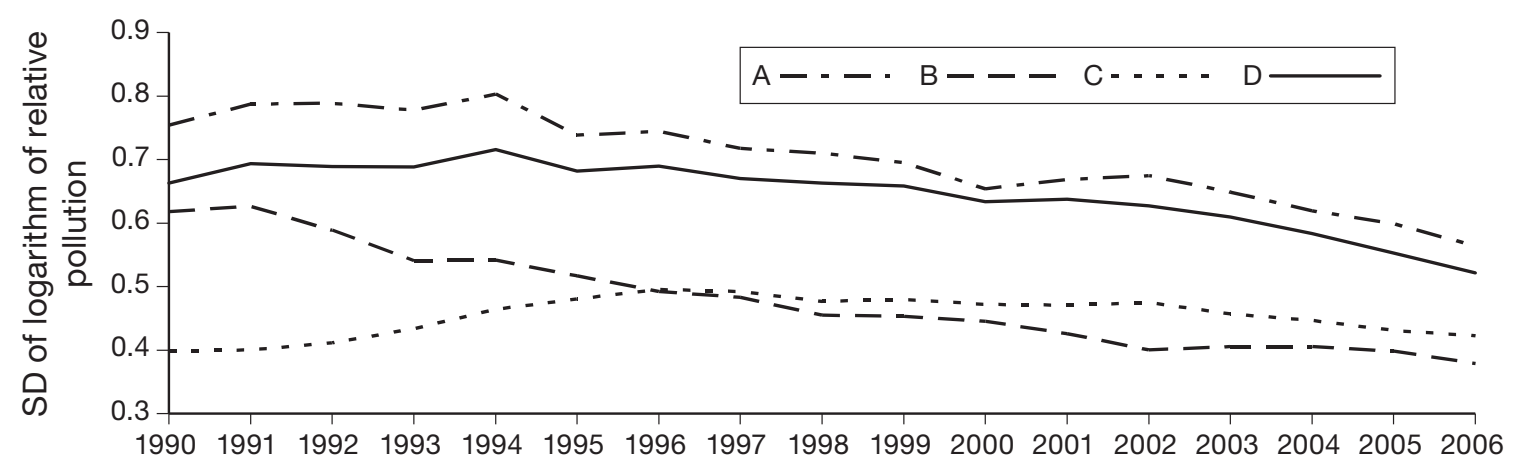

Fig. 2. Trends of standard deviations $(\sigma)$ of logarithms of relative annual pollution: (A) acidifying substances, (B) greenhouse gases, (C) ozone precursors, and (D) particulate matter. Calculations based on Eurostat and The Conference Board and Groningen Growth and Development Centre, Total Economy Database data 

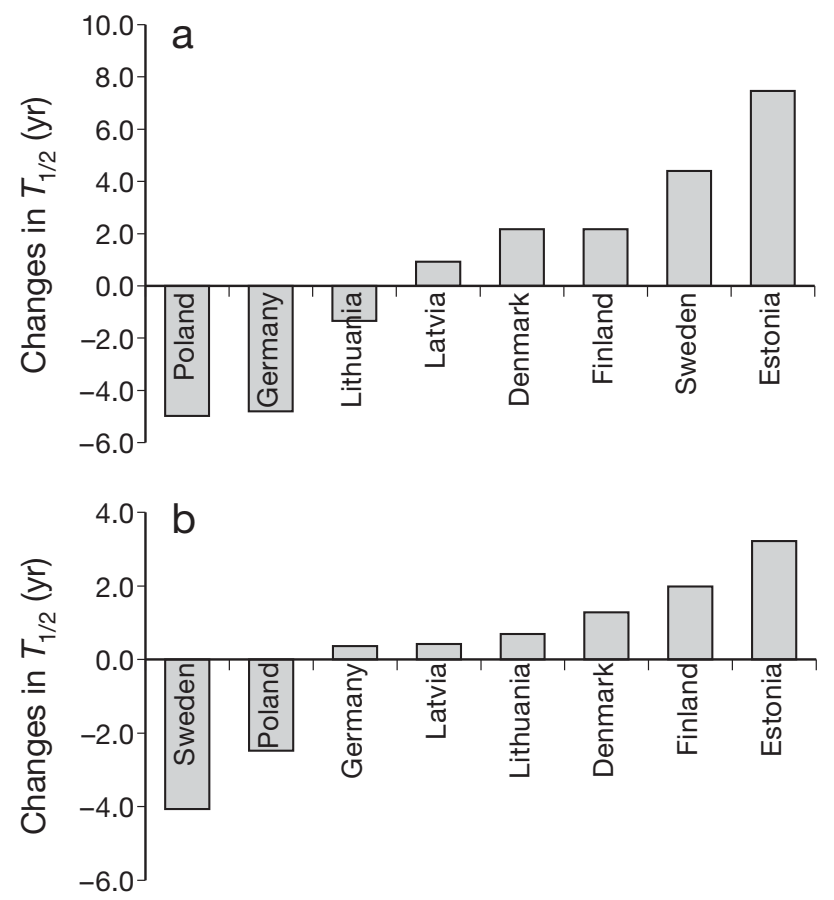

Fig. 3. Changes in the half-life of convergence $\left(T_{1 / 2}\right)$ for relative annual emission of (a) acidifying substances and (b) greenhouse gases (Pollution A and B, respectively). Calculations based on Eurostat and The Conference Board and Groningen Growth and Development Centre, Total Economy Database data

\section{CONCLUSIONS}

One of the main findings of the present research is that the trends in the relative emission of pollution in the BSR are diminishing. It is important to mention that the decrease in relative pollution levels in the newer EU members was caused by the growth in their GDP, while changes in the absolute pollution levels were very small ${ }^{3}$. These results confirm the increase in the ecological effectiveness of the analyzed economies.

The biggest decrease in relative pollution levels was observed for countries with higher initial levels of pollution. The highest absolute values of pollution were in Germany and Poland.

Significant convergence exists for 3 types of pollution (A, B, and D), as demonstrated by the methodology of $\beta$ - and $\sigma$-convergence. This convergence is equivalent to the degree of 'environmental friendliness' of the BSR economies becoming more similar to one another.

However, the influence of individual countries' pollution levels on the overall speed of convergence is different. These different speeds were demonstrated

\footnotetext{
${ }^{3}$ See also results obtained by Alvarez et al. (2004)
}

using the idea of marginal vertical convergence. This conclusion agrees with the empirical findings obtained by Alvarez et al. (2004), who stated that the heterogeneity of pollution levels among countries does not appear to be associated with substantial differences in production technologies or the sources of emissions of pollution but rather is implied by region-specific differences that can be related to the level of economic development and to the output growth.

\section{LITERATURE CITED}

Aghion P, Howitt P (1999) Endogenous growth theory. MIT Press, Cambridge, MA

Alvarez F, Marrero GA, Puch LA (2004) Air pollution convergence and economic growth across European countries. Documentos del Instituto Complutense de Análisis Económico, no. 0406. Facultad de Ciencias Económicas y Empresariales, Universidad Complutense de Madrid

Barro R, Sala-i-Martin X (2004) Economic growth. MIT Press, Cambridge, MA

Batóg J, Batóg B (2006) Income convergence in the European countries: empirical analysis. Folia Oeconomica Stetinensia 5(13):129-142. Available at: http://usfiles.us.szc.pl/ getfile.php?pid $=4902$

Bernard AD, Durlauf SN (1995) Convergence in international output. J Appl Econ 10:97-108

Criado CO, Valente S, Stengos T (2009) Growth and the pollution convergence hypothesis. A nonparametric approach. Centre for Energy Policy and Economics (CEPE) Work Pap 66. Swiss Federal Institutes of Technology, Zurich

Ebi KL, McGregor G (2008) Climate change, tropospheric ozone and particulate matter, and health impact. Environ Health Perspect 116:1449-1455

EEA (European Environment Agency) (2004) Impacts of Europe's changing climate. An indicator-based assessment. EEA Rep 2. EEA, Copenhagen. Available at: www. eea.europa.eu/publications/climate_report_2_2004

European Commission (2010) Proposal for a regulation of the European Parliament and of the Council on European environmental economic accounts (text with EEA relevance). Doc. no. COM(2010)132 final, 2010/0073 (COD). European Commission, Brussels. Available at: http://eurlex.europa.eu/LexUriServ/LexUriServ.do?uri=COM:2010: 0132:FIN:EN:PDF

Goossens Y, Mäkipää A, Schepelmann P, van de Sand I, Kuhndtand M, Herrndorf M (2007) Alternative progress indicators to Gross Domestic Product (GDP) as a means towards sustainable development. Study no. IP/A/ENVI/ ST/2007-10, doc. no. PE 385.672. Policy Department Economic and Scientific Policy, European Parliament, Brussels. Available at: www.europarl.europa.eu/activities/ committees/studies/download.do?file $=19990$

Harris PG (2008) Climate change and global citizenship. Law Policy 30:481-501

Heil MT, Wodon QT (1999) Future inequality in carbon dioxide emissions and the projected impact of abatement proposals. World Bank Policy Res Work Pap 2084. World Bank, Washington, DC. Available at: http://www-wds. worldbank.org/external/default/main?pagePK=64193027 \&piPK=64187937\&theSitePK=523679\&menuPK=64187510 \&searchMenuPK=64187283\&theSitePK=523679\&entityID =000094946_9904120637066\&searchMenuPK=64187283\& 
theSitePK=5236790

Jiang K, Morita T, Masui T, Matsuoka Y (2000) Global longterm greenhouse gas mitigation emission scenarios based on AIM. Environ Econ Policy Stud 3:239-254

Kerr A (2007) Serendipity is not a strategy: the impact of national climate programmes on greenhouse-gas emissions. Area 39:418-430

Nishioka Y, Levy JI, Norris GA (2006) Integrating air pollution, climate change, and economics in a risk-based lifecycle analysis: a case study of residential insulation. Hum Ecol Risk Assess 12:552-571

Stegman A (2005) Convergence in carbon emissions per

Submitted: December 1, 2009; Accepted: March 11, 2011 capita. Centre for Applied Macroeconomic Analysis (CAMA) Work Pap 8/2005. Australian National University, Canberra. Available at: http://cama.anu.edu.au/Working \%20Papers/Papers/2005/Stegman82005.pdf

Stiglitz JE, Sen A, Fitoussi JP (2009) Report by the Commission on the Measurement of Economic Performance and Social Progress. Commission on the Measurement of Economic Performance and Social Progress, Paris. Available at: www.stiglitz-sen-fitoussi.fr/en/index.htm

Strazicich MC, List JA (2003) Are $\mathrm{CO}_{2}$ emission levels converging among industrial countries? Environ Resour Econ 24:263-271

Proofs received from author(s): May 297, 2011 